University of Colombo Review (Series III),

Vol. 1, No. 1, 2020

\title{
Making Sense of the Haze: Hedging and its Attributes
}

\author{
Shakthi De Silva \\ Assistant Lecturer, Department of International Relations, Faculty of Arts, University of Colombo
}

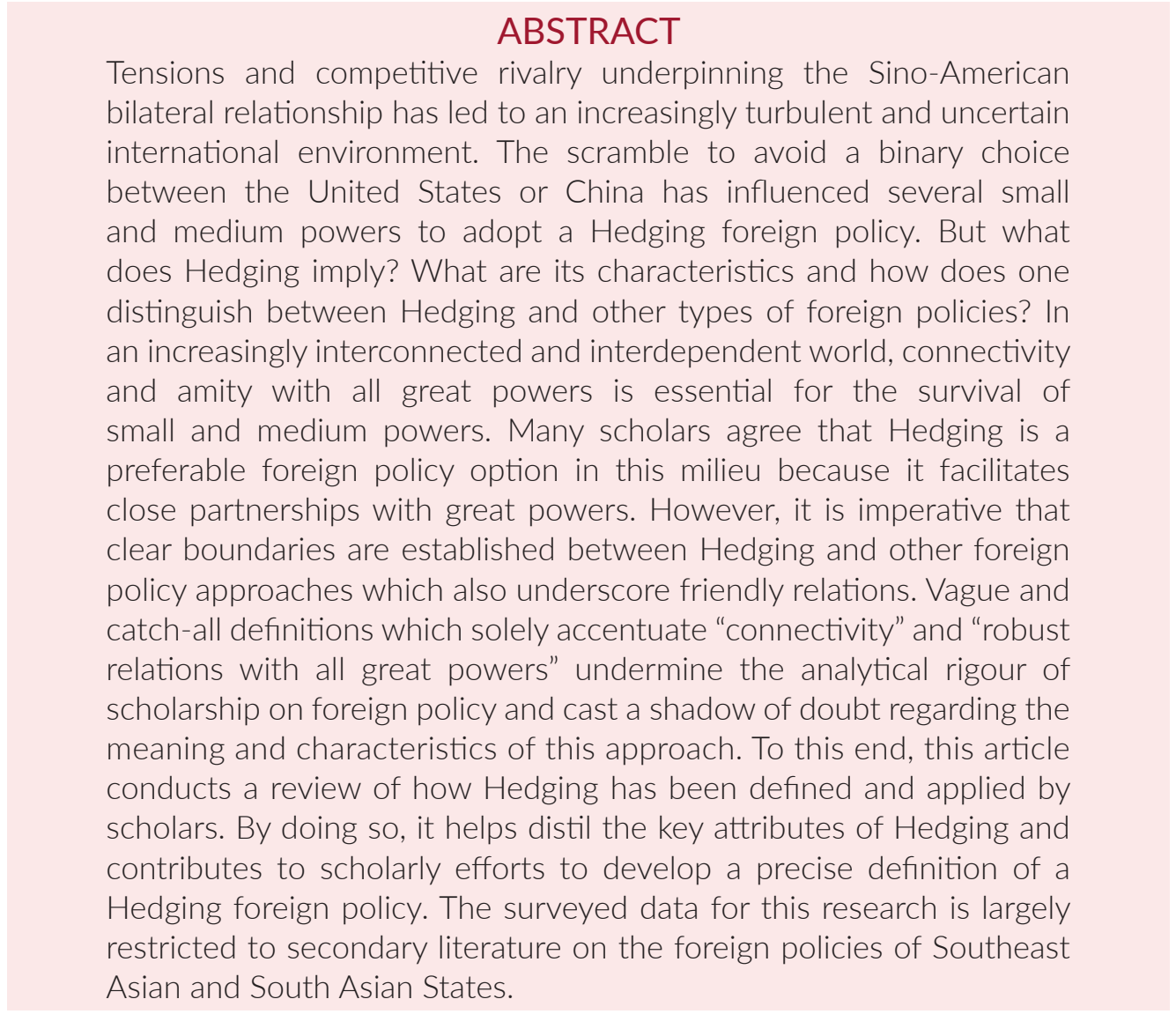

KEY WORDS:

Hedging, foreign policy, Southeast Asia, South Asia

Suggested Citation: De Silva, S. Making Sense of the Haze: Hedging and its Attributes. University of Colombo Review (Series III). 1 (1). 94 - 100

(C) 2020 The Authors. This work is licenced under a Creative Commons Attribution 4.0 International Licence which permits unrestricted use, distribution, and reproduction in any medium, provided the original work is properly cited. 


\section{The Definitions and Application of Hedging}

In their introductory article "Hedging in International Relations: An introduction", John Ciorciari and Jürgen Haacke raise an important concern in relation to the foreign policy strategy referred to as Hedging. They argue that existing definitions forwarded by scholars "stretches the idea of hedging too far" to "encompass any strategy that mixes cooperative and self-protective elements" (2019, p. 370). Owing to a surge in its usage among the foreign policy community, it is imperative that this contested concept and its constituents are perspicuously understood. "Hedging" was originally employed to explain the risk contingency measure of investing in more than one party to offset potential loss. The idiom "hedging one's bets" for example, describes the action of protecting one's investment by supporting more than one possible result or both sides in a competition. The term, as conceptualized by International Relations scholars, did not significantly depart from the original explanation and was chiefly applied to explicate the foreign policies of Southeast Asian states (He \& Li, 2020, p. 3).

Tectonic shifts occurring in the international domain as a result of China and the United States entering into a "new era of great power competition" has become one of the defining features of the 21st Century. Ann Marie Murphy contends that in this milieu, Hedging emerges as an expedient foreign policy strategy for most Southeast Asian countries owing to the "economic incentives offered by China" and the disincentives created by U.S. pressure to protect democratic practices and human rights (Murphy, 2017, p. 165). Despite Beijing's aggressive behaviour in the South and East China seas, Southeast Asian leaders remain reluctant to adopt an assertive balancing foreign policy with the United States against China. Similarly, a fear of abandonment, exploitation and over-reliance on China prevents Southeast Asian states from bandwagoning with Beijing. Scholars tend to agree, therefore, that most, if not all, Southeast Asian states adopt a Hedging foreign policy.

The principal indicators of Hedging in this scholarship include:

- strengthening of the military without a declared adversary, chiefly through the U.S. anchored bilateral hub-and-spoke system;

- increased participation in bilateral and multilateral cooperation networks;

- absence of firm balancing or bandwagoning; and

- simultaneous improvement in relations with the two great opposing powers (Jackson, 2014, p. 333).

Engagement with opposing powers is highlighted as a hallmark of a Hedging foreign policy in Fiori and Passeri's study of Myanmar's external relations in which they discuss at length how Myanmar cultivated a robust diplomatic and economic relationship with Beijing while, at the same time, welcoming and encouraging Washington's growing engagement in the region. Hedging, in their view, is a

set of multidimensional insurance and engagement policies adopted by small actors in their relations vis-a-vis great powers that avoids the choice of one side at the obvious expense of another as well as one more straightforward policy stance such as in the case of classic balancing or bandwagoning. (2015, p. 683) 
Goh offers a somewhat similar argument. She contends that Hedging is a strategy where "engagement policies are pursued at the same time as indirect balancing policies" (2006, p. 1). Indirect balancing policies involve countering the target state's ability to constrain the subject state (or the state adopting the Hedging posture) through "defense strengthening or through building diplomatic, economic and political relationships with third states or organizations that can be converted into leverage against the target state when relations deteriorate" (p. 1).

Others simply see Hedging as a bundle of opposite and deliberately ambiguous policies vis-a-vis competing great powers, aimed at maintaining a fall-back position (Kang, 2007, p. 53). A Joint U.S. - Korea Academic Studies publication amends this parsimonious description by adducing several core traits of a Hedging foreign policy:

- not taking sides among competing powers

- adopting opposite and counteracting measures

- using mutually counteracting acts to preserve gains and cultivate a fall-back position (Rozman, 2015, p. 2).

In their treatment of Hedging in South Asia, Lim and Mukherjee interrogate the behaviour of South Asian states and conclude that these states engage in "contradictory or counteracting policy" postures (2019, p. 495). To them, Hedging is a foreign policy that has utility in the face of actual or potential threats from either of the two competing powers as well as in the absence of the same. However, a drawback in this study is the authors' inability to adequately provide examples for contradictory and counteracting policies in state behaviour, particularly with reference to Sri Lanka's foreign policy. A case in point is their account of the Sirisena administration's decision to temporarily halt and later resume Chinese development projects in Sri Lanka (Lim \& Mukherjee, 2019, p. 513). In their view, this exhibits Sri Lanka's contradictory foreign policy. Missing from their narrative, however, is the fact that the Sirisena-Wickremasinghe coalition campaigned in 2015 on the promise of investigating Chinese development projects in the island. Once in power, this pledge culminated in a temporary halting of several projects, pending investigations and feasibility appraisals. The halted projects resumed operations after the Sri Lankan government assessed its commitments to Chinese and other foreign lenders. At the time, extending the temporary halt to a permanent one would have resulted in the payment of substantial financial compensations to Chinese companies. By considering this temporary interval as indicative of Sri Lanka's desire to send "ambiguous alignment signals" via a contradictory foreign policy (2019, p. 495), Lim and Mukherjee overlook the financial obligations that Sri Lankan policymakers had to consider when arriving at a decision.

Lim and Cooper's study on East Asian states identified Hedging as "a class of behaviours which signal ambiguity regarding great power alignment, therefore requiring the state to make a trade-off between the fundamental (but conflicting) interest of autonomy and alignment" (2015, p. 703). A similar study articulated Hedging as "a set of multiple approaches, which act simultaneously as a strategy to help the employing states minimize their threats while maximizing their opportunities in relations with other nations in an uncertain environment" (Tran and Sato, 2018, p. 77). A close examination 
of these definitions reinforces the argument that mixed signals, defined in scholarship as "counteracting acts" (Rozman, 2015, p. 2), "contradictory or counteracting policy" (Lim \& Mukherjee, 2019, p. 495), "ambiguity” (Lim \& Cooper, 2015, p. 703) and "pursuing different options simultaneously" (Edström \& Westberg, 2020, p. 177), is a key element in a Hedging foreign policy posture.

Most definitions describe Hedging as a strategy which enables small states to maximize benefits from great powers through diverse forms of engagement while also generating risk contingency measures. This emphasis on the contingency element is a subtle but important distinction which can help us differentiate Hedging from other foreign policy strategies such as neutralism. While neutralism enables states to continue robust engagement to maximise national interests, it does not entail an element of contingency planning. Most scholars agree that Hedging must incorporate an insurance policy in the event engagement fails (Koga, 2017, p. 636; Han and Paul, 2020, p. 8-13), although a few drop this characteristic in their definition. Seng Tan, for example, identifies Hedging as a "state's active (even vigorous) engagement with great powers and countries of inordinate influence without jeopardizing its relations with any" (2011, p. 162). Naturally, adhering to Tan's definition complicates our efforts to distinguish between Hedging and other foreign policy strategies such as neutralism.

Korolev (2019) also ostensibly conflates Hedging with neutralism. He argues that Hedging implies "a type of state behaviour that emphasizes relative equidistance in relations with other powers and combines engagement and containment" (Korolev, 2019, p. 420). He adds that Hedging is premised on the notion that states simultaneously improve relations in an equidistant manner to avoid over reliance on one power. This latter point, however, makes it difficult to distinguish between Hedging and a neutral foreign policy posture. Furthermore, according to Korolev, Hedging is more directly affected by non-systemic causal factors, or in other words unit level variables; an argument that few scholars have hitherto discussed in their research.

The most comprehensive analysis of Hedging thus far has been forwarded by ChengChwee. Hedging, in his view, emerges as an attractive policy owing to the fact that it is an insurance seeking strategy: both return-maximizing and consisting of a risk contingency element. For example, by applying it to Malaysia's foreign policy, Cheng-Chwee exposes how the "Najib government [of Malaysia] has sought to hedge by concurrently enhancing Malaysia's ties with America and China, building stronger bilateral relationships with both powers without departing from its non alignment stance, all with an eye to reinforcing its fall back position" (2016, p. 169).

Cheng-Chwee argues that a Hedging foreign policy is determined by three factors:

- the absence of an immediate threat (that might compel a state to ally with a power for protection);

- the absence of any ideological fault-lines (that might rigidly divide states into opposing camps); and

- the absence of an all-out great power rivalry (Cheng-Chwee, 2008, p. 165).

$\mathrm{He}$ also goes on to list five different approaches of a Hedging foreign policy. 
1. Economic Pragmatism refers to a "policy wherein a state seeks to maximise economic gains from its direct trade and investment links with great powers regardless of any political problems between them" (Cheng-Chwee, 2008, p. 167). Over time, this would enable states to enhance socio-economic linkages with great powers which help cement closer engagement between their bureaucracies.

2. Binding Engagement is based on the desire of states to neutralize the revisionist tendencies of a great power. Through close diplomatic interaction with great powers, states aim to alter great power policy choices. This Hedging strategy also involves binding the great power to various "institutionalized bilateral and multilateral platforms" (Cheng-Chwee et al., 2012, p. 319).

3. Limited bandwagoning refers to the act of developing political partnerships with great powers through "(a) policy coordination of selective issues; and (b) voluntary deference given to the larger partner" (Cheng-Chwee, 2008, p. 168). Limited bandwagoning differs from pure bandwagoning on three accounts. Firstly, limited bandwagoning only involves political partnerships and not military alignments. Secondly, it allows states to develop political ties with the rising power while maintaining its relations with the existing hegemon. Lastly, limited bandwagoning enables states to avoid losing their autonomy in decision-making.

4. By involving other partners into regional affairs and developing collective diplomatic clout, states can deny the dominance of one hegemon in a particular area. Cheng-Chwee terms this Hedging approach dominance denial.

5. Finally, an indirect balancing Hedging foreign policy requires states to forge defence cooperation and upgrade the country's military without specifying a particular threat. Instead, the state maintains that such defence cooperation is required to deal with "diffused uncertainties" (Cheng-Chwee, 2008, p. 170).

These approaches, though distinct from one another, do not necessarily have to be applied individually to a single case study. Some scholars argue that a country can adopt a mix or combination of these strategies, as clearly illustrated by Ling's application of several approaches denoted above, to delineate Cambodia's foreign policy (Ling, 2017, p. 328-347).

Hedging is generally believed to best explain the behaviour of small and medium powers because the power gap between them and great powers makes a balancing or bandwagoning approach appear costly and unnecessarily risky. Hedging is expected to reduce the risk of entrapment as well as grant greater leeway for small and medium powers to maintain an alignment with the dominant power, as well as simultaneously pursue robust political and economic engagement with the dominant power's rival. Medeiros, however, challenges this conventional usage of Hedging as a policy adopted by Southeast and South Asian states with regard to their relations with the United States and China. Instead, he posits that the United States and China hedge by "engagement and integration mechanisms" as well as through "realist-style balancing in the form of external security cooperation with Asian states and national military modernization programs" (2005, p. 145). 


\section{Conclusion}

How has Hedging been understood and applied in International Relations research? Firstly, Hedging as a term is primarily utilized to explain the foreign policy postures of several Southeast Asian countries but is also increasingly applied in discussions on the foreign policies of South Asian countries. One needs to clarify what Hedging entails as well as the structural preconditions required for a Hedging foreign policy to plausibly conclude that a particular foreign policy indicates a case of Hedging.

Has Hedging served as a catch-all rubric in scholarly literature? While some definitions appear to be too expansive, most interpretations of Hedging do not overlap with other foreign policies. Preconditions for the application of a Hedging foreign policy include the absence of an immediate threat to the state from its external environment (Haacke, 2019 , p. 3) and ingrained ideological perspectives which would otherwise position the country within the orbit of a particular camp.

By distilling diverse scholarly definitions of Hedging, this review article has endeavoured to distinguish the core characteristics of a Hedging foreign policy. Hedging is generally applied in cases where small and medium powers attempt to build ties with China and the United States concurrently (Goh, 2006, Jackson, 2014; Korolev, 2019; Tan, 2011). Hedging therefore, implies that states will simultaneously build ties with great powers despite their bilateral acrimony.

Ambiguity is a core element in a Hedging foreign policy as it enables small and medium powers to navigate between great powers without depending on, or over-relying on either great power (Kang, 2007; Lim \& Cooper, 2015). To quote Shambaugh,

The whole purpose of hedging is to avoid becoming too close - and hence too dependent - on any external power. Alignment behavior, by contrast, willingly accepts some degree of dependency and seeks to align a smaller country with a larger power. (2018, p. 94)

Furthermore, mixed signals enable small and medium powers to maintain an appearance of not being partial or biased towards either of the rival great powers. While strengthening ties with the rising power, states adopting a Hedging foreign policy also secure a fall-back position. Most often this involves continuing or augmenting military ties with the dominant power - i.e. the United States (Fiori \& Passeri, 2015; Kang, 2007; Koga 2017; Rozman, 2015). These are the principal characteristics that capture the essence of a Hedging foreign policy.

While this review article highlighted the core attributes of a Hedging foreign policy, it is imperative that further research be conducted to establish clearer empirical evidence of what Hedging is, what it implies and what distinguishes it from alternative foreign policy approaches such as balancing, bandwagoning, omnibalancing, omni-enmeshment and neutrality as applied to South Asian and Southeast Asian case studies.

\section{References}

Cheng-Chwee, K. (2008). The essence of Hedging: Malaysia and Singapore's response to a rising China. Contemporary Southeast Asia, 30(2), 159-185. 
Cheng-Chwee, K. (2016). Malaysia between the United States and China: what do weaker states Hedge against? Asian Politics \& Policy, 8(1), 155-177.

Cheng-Chwee, K., Idris. A., \& Nor. R. (2012). The China factor in the U.S. reengagement with South East Asia: Drivers and limits of converged hedging. Asian Politics and Policy, 4(3), 315-344.

Ciorciari, J., \& Haacke, J. (2019). Hedging in International Relations: An introduction. International Relations of the Asia-Pacific. 19(3), 367-374.

Edström, H., \& Westberg, J. (2020). The defense strategies of middle powers: Competing for security, influence and status in an era of unipolar demise. Comparative Strategy, 39(2), 171-190.

Fiori A., \& Passeri, A. (2015). Hedging in search of a new age of non-alignment: Myanmar between China and the USA. The Pacific Review, 28(5), 679-702.

Goh, E. (2006). Understanding 'hedging' in Asia-Pacific security. PacNet (43), 1-2.

Haacke, J. (2019). Time to revisit Hedging. Relazioni internazionali e International political economy del Sud-Est asiatico (RISE), 4(1), 2-4.

Han, Z., \& Paul, T. V. (2020). China's rise and balance of power politics. The Chinese Journal of International Politics, 13(1), 1-26.

He, K., \& Li, M. (2020). Understanding the dynamics of the Indo-Pacific: US-China strategic competition, regional actors, and beyond. International Affairs, 96(1), 1-7.

Jackson, V. (2014). Power, trust and network complexity: Three logics of Hedging in Asian Security. International Relations of the Asia Pacific, 14(3), 331-356.

Kang, D. (2007). China rising: peace, power and order in East Asia. Columbia University Press.

Koga, K. (2017). The concept of 'Hedging' revisited: the case of Japan's foreign policy strategy in East Asia's power shift. International Studies Review, 20(4), 633-660.

Korolev, A. (2019). Shrinking room for hedging: system-unit dynamics and behavior of smaller powers. International Relations of the Asia-Pacific, 19(3), 419-452.

Lim D., \& Cooper, Z. (2015). Reassessing Hedging: the logic of alignment in East Asia. Security Studies, 24(3), 696-727.

Lim, D., \& Mukherjee, R. (2019). Hedging in South Asia: balancing economic and security interests amid Sino-Indian competition. International Relations of the Asia-Pacific, 19(3), 493-522.

Ling, T. (2017). Small state diplomacy: Cambodia's foreign policy towards Vietnam. The Pacific Review, 30(3), 328-347.

Medeiros, S. (2005). Strategic Hedging and the future of Asia-Pacific stability. The Washington Quarterly, 29(1), 145-167.

Murphy, A. M. (2017). Great power rivalries, domestic politics and Southeast Asian foreign policy: exploring the linkages. Asian Security, 13(3), 165-182.

Rozman, G. (2015). Introduction. In Rozman G., (Ed), East Asia: Facing tough decisions on competition and cooperation (pp. 1-10). Korea Economic Institute of America.

Shambaugh, D. (2018). U.S.-China rivalry in Southeast Asia: Power shift or competitive coexistence? International Security, 42(4), 85-127.

Tan, S. S. (2011). America the Indispensable: Singapore's view of the United States' engagement in the Asia-Pacific. Asian Affairs: An American Review, 38(3), 156-171.

Tran, B., \& Sato, Y. (2018). Vietnam's post-Cold War hedging strategy: A changing mix of realist and liberal ingredients. Asian Politics \& Policy, 10(1), 73-99. 